\title{
Individual fish rhythm directs group feeding: a case study with sea bass juveniles (Dicentrarchus labrax) under self-demand feeding conditions
}

\author{
Sandie Millot and Marie-Laure Bégout ${ }^{\mathrm{a}}$ \\ Ifremer, LRHLR, place Gaby Coll, BP 5, 17137 L'Houmeau, France
}

Received 20 July 2009; Accepted 5 October 2009

\begin{abstract}
The long term influence of individual biological rhythms on group feed demand behaviour was investigated in European sea bass (Dicentrarchus labrax) held under controlled environmental conditions with an on-demand feeding system. The experiment was realized over 219 days with 190 fish distributed on 4 tanks. Sea bass had a mean body mass comprised between $139 \mathrm{~g}$ to $183 \mathrm{~g}$. The number of feed demand acts by each individual was calculated daily, and the population could thus be partitioned into three categories (high-, low- and zero-triggering fish). The duration of the period that an individual held high-triggering status could vary, but was $63 \pm 16$ days on average. The transition period between two highest-triggering fish in one tank was on average $4 \pm 4$ days. The group feeding rhythm followed the same pattern of feed demand rhythm as the highest-triggering individual fish. When the highest-triggering fish was nocturnal, the totality of feed demand in the group was realized during the night with one peak at 22:00, corresponding to dusk under experimental conditions. When the highest-triggering fish was diurnal, the majority of feed demand in the group was realized during the light period with one peak at 06:00, corresponding to dawn, and/or another at 12:00. This study therefore highlights that sea bass group feeding behaviour is not the sum of individual feed demand behaviours, but is directed by the rhythm and behaviour of a few high-triggering fish. The regular changes of high-triggering fish in the group proved that it was not the identity of these particular fish that was most important for the group, but their role as a feed demand leader.
\end{abstract}

Key words: Feeding rhythms / Feed demand leader / Social interactions / Self-feeder / Dicentrarchus labrax

\begin{abstract}
Résumé - L'influence à long terme des rythmes biologiques individuels sur le comportement alimentaire du groupe est étudiée sur des bars européens (Dicentrarchus labrax) maintenus dans des conditions environnementales contrôlées et avec un système d'alimentation à la demande. L'expérience est réalisée sur 219 jours avec 190 poissons répartis dans 4 bassins. Les bars ont un poids corporel moyen compris entre $139 \mathrm{~g}$ à $183 \mathrm{~g}$. Le nombre de demande alimentaire réalisée par chaque individu est calculé quotidiennement, et la population a pu être divisée en trois catégories (manipulateur principal, occasionnel et non manipulateur). La durée pendant laquelle un manipulateur principal reste actif peut varier, mais elle est en moyenne de $63 \pm 16$ jours. La période de transition entre deux manipulateurs principaux dans un bassin est en moyenne de $4 \pm 4$ jours. Le rythme alimentaire du groupe suit le même patron que celui du manipulateur principal. Lorsque le manipulateur principal est nocturne, la totalité des demandes alimentaires du groupe est réalisée pendant la nuit avec un pic à 22:00, correspondant au crépuscule dans les conditions expérimentales. Lorsque le manipulateur principal est diurne, la majorité des demandes alimentaires du groupe est réalisée pendant la période d'éclairement, avec un pic à 06:00, correspondant à l'aube, et/ou un autre à 12:00. Cette étude souligne donc que le comportement alimentaire des bars, en groupe, n'est pas la somme des comportements individuels de demande alimentaire, mais est dirigé par le rythme et le comportement de quelques manipulateurs principaux. Le changement régulier des manipulateurs principaux dans le groupe prouve que ce n'est pas l'identité de ces poissons particuliers qui est le plus important pour le groupe, mais leur rôle comme «leader » de la distribution alimentaire.
\end{abstract}

\section{Introduction}

Feeding behaviour is the basis of one of the most important vital functions for fish, their nutrition (Sánchez-Vázquez

\footnotetext{
a Corresponding author: marie.laure.begout@ifremer.fr
}

et al. 1994). Under natural conditions, food availability is one of the most important environmental factors that affect an animal's survival. To improve food acquisition, animals have developed several systems to synchronize feeding times with their behavioural activities, hormonal levels and many other 
physiological variables (Boulos and Terman 1980). Therefore, in relation to natural diel and seasonal variation of food availability in the wild, feeding activity in fish shows a diel pattern even under controlled conditions (Sánchez-Vázquez et al. 1994).

Sea bass (Dicentrarchus labrax) displays flexibility in its feeding rhythms (Anthouard et al. 1993; Sánchez-Vázquez et al. 1994, 1995a; Boujard et al. 1996). Many daily and seasonal rhythms are endogenously driven by the circadian system and synchronized by external cyclical cues with a stable periodicity, called zeitgebers (Falcon et al. 1992; Sánchez-Vázquez et al. 1995a; Madrid et al. 2001). Under natural conditions (Bégout Anras 1995) as well as under controlled laboratory conditions (Sánchez-Vázquez et al. 1995b; Aranda et al. 1999), sea bass display a dual phasing behaviour in their circadian feeding pattern. Sea bass exhibit both nocturnal and diurnal feeding behaviour: they are predominantly diurnal in summer, nocturnal in winter and then return to diurnal behaviour in spring (Madrid 1994; Sánchez-Vázquez et al. 1995b; Sánchez-Vázquez et al. 1998). This diurnal/nocturnal behaviour of sea bass has been described in relation to seasonal variations in photoperiod and water temperature (Bégout Anras 1995), sudden changes in environmental conditions (Anthouard et al. 1993; Sánchez-Vázquez et al. 1995b) and several intrinsic factors such as motivational level, and visual (Bardach and Todd 1970) and social stimuli (Kentouri et al. 1986). Among the studies cited above, many used on-demand feeding systems but the relative individual contribution to feed demand was seldom investigated (Covès et al. 2006; Di-Poi et al. 2008; Millot et al. 2008). It has however been pointed out that individual roles could direct group feeding under environmentally controlled conditions (Millot et al. 2008).

With the aim of determining the stability of biological feeding rhythms in individual sea bass and the relative role of an individual in the group over time, we designed a long term controlled experiment (219 days) with no intervention except measurements of weight and length. The data set was first presented in Millot et al. (2008) with a focus on individual specific growth rate variation and health. The present paper offers another analysis with a focus on i) the rhythm of role changes between individuals of the group, and ii) daily demand-feeding rhythms of individual fish and the way in which these direct the timing of feeding in the whole group.

\section{Materials and methods}

\subsection{Apparatus}

The device to operate the feeders comprised a screened type sensor (a metal rod protected in a PVC cylinder surrounded by the PIT tag detection antenna (Covès et al. 2006; Millot et al. 2008) and a control box. After each actuation, fish were rewarded with feed pellets; the feed dispensers were regulated to distribute between $0.5 \mathrm{~g} \mathrm{~kg}^{-1}$ of fish live weight at the beginning and $0.4 \mathrm{~g} \mathrm{~kg}^{-1}$ at the end of the experiment, which represented around 50 pellets per actuation. Each individual had been horizontally PIT-tagged by inserting a tag just behind the head, allowing individual identification when fish activated the feeder rod. With this set up, we were able to record the number of feed demand acts by all individuals and thus monitor both individual and group feeding behaviour on an hourly and daily basis.

\subsection{Experimental set up}

Sea bass were hatched in "Aquanor" (France) and grown at "Ferme Marine des Baleines -Aquapole" (France). At the beginning of the study, the fish were 13 months old. In one single experimental room, four $400 \mathrm{~L}$ seawater tanks were supplied with the same sand-filtered water in a recirculated system (flow rate of $4 \mathrm{~m}^{3} \mathrm{~h}^{-1}$ and $10 \%$ water renewal per day). Water temperature was maintained at $22.2 \pm 1.5^{\circ} \mathrm{C}( \pm \mathrm{SE})$, the oxygenation was above $70 \%$ saturation in the outlet and salinity was $28.6 \pm 3.3$. Ammonia and nitrite levels in the water were measured each experimental day and never exceeded recommended levels for sea bass. Tanks were surrounded by black curtains and each was equipped with a $120 \mathrm{~W}$ lamp (240 V, PAR 38 FLOOD, OSRAM $\left.{ }^{\circledR}\right)$, placed at $90 \mathrm{~cm}$ above the water surface (900 lux measured $20 \mathrm{~cm}$ above the water surface). Light regime was 16:8 LD, with light onset at 06:00 U.T. +1 (Universal Time +1 corresponding to European winter time) with twilight transition periods of 30 minutes. Fish were fed with a commercial sea bass diet (Neo Grower Extra Marin 4.0, France: $45 \%$ crude protein, $20 \%$ lipid according to the manufacturer, $4 \mathrm{~mm}$ ).

The experiment was realized over 219 days, with $n=$ 190 fish in 4 tanks: 50 fish per tank in three tanks and 40 larger fish in the fourth in order to minimize fish size variation and to reach the same initial biomass. At the beginning of the study sea bass had a mean body mass of $139 \pm 1 \mathrm{~g}$ (coefficient of variation $(C V)=11 \%, n=150$ ) for tanks 1,2 and 3 and of $183 \pm 3 \mathrm{~g}(C V=10 \%, n=40)$ for tank 4 , biomass was in the range $6.9-7.3 \mathrm{~kg}$.

During the 219 days of the experiment, 11 fish died (some jumped out of the tank and others died of unknown causes). These changes in number of individuals were taken into account for all variables measured.

Fish were placed under self-feeding conditions from the first day of the experiment (following one week of acclimation) with $24 \mathrm{~h}$ food access, even during the cleaning of the rearing unit and waste counting from 10:00 to 11:00 U.T.+1 (uneaten pellets were counted on the bottom of each tank and in the sediment traps). Triggering activity recordings were made continuously for 219 days except during the periods before and during fish measurement which required $24 \mathrm{~h}$ of fasting in advance and therefore no feeding data during this time (15 days off in total). There were also 11 days when triggering activity was not recorded due to a software problem. We therefore obtained a total of 193 days of feeding activity recordings. On the measurement days, days 25, 80, 148, 197 and 219, fish were manipulated under light anaesthesia with $0.08 \%$ clove oil. Fish mass was measured to the nearest $\mathrm{mg}$ and fish length to the nearest $\mathrm{mm}$.

\subsection{Data analysis}

Individual and group feeding behaviour were first examined by determining triggering activity of the individual fish 
(i.e. number of feed demand acts by each individual fish) and the resulting group composition based on numbers of fish with different levels of triggering activity, classed into three categories. The number of feed demand acts per individual was used to calculate the proportional contribution of an individual fish to the total number of trigger actuations within its group over the experimental period and to assign the individual to one of the categories: high-triggering ( $>25 \%$ actuations) during their most active period, low-triggering $(<25 \%)$ and zerotriggering $(0 \%)$ individuals (Covès et al. 2006; Di poi et al. 2008; Millot et al. 2008). The duration of the high-triggering activity of each individual was calculated in days.

To evaluate the high-triggering fish feeding rhythm in each tank, the number of feed demand acts were summed per hour and the resulting variable analyzed using an actogram. To evaluate the low-triggering fish contribution to the group feeding, the number of feed demand acts realized by all low-triggering fish was summed per day. To establish the individual and group feeding rhythm, every clock hour feed demand acts sums were averaged over the entire experimental period.

Additionally, total daily feed demand acts for each group and for each high-triggering fish were converted into feed quantity and expressed relative to fish biomass present in the tank. It was calculated as: [(total daily feed demand acts $\times$ feed quantity distributed per actuation $\times 100) \times($ biomass present in the tank for the period considered $)^{-1}$ ].

All mean values were expressed with the standard error (SE).

All data were first tested for normality with a Shapiro-Wilk test and for homoscedacity of variance with a Bartlett's test, which showed that they complied with the rules for parametric statistics. One-way ANOVA was then used to compare all variables between tanks or between high-triggering fish. Homogeneous groups were determined with the a posteriori Newman and Keuls test (Dagnélie 1975). For all tests, the significance threshold was $p<0.05$ and analyses were performed using Statistica software.

\section{Results}

\subsection{Categories of triggering activity and daily feed demand}

As there was a learning period, the self-feeder activation allowing a real meal (about $1 \%$ of fish biomass) occurred about 10 days after the experiment started, for all high and low triggering fish in tanks 1,2 and 3. Tank 4 showed real self-feeder activation only from the 50th day.

The partitioning of the groups of fish in each tank into the three triggering categories was compared and no tank effects was observed $\left(F_{3,186}=1.25, p>0.05\right)$, which allowed data to be pooled among tanks. Indeed, the 4 groups were composed of $10 \pm 3 \%$ zero-triggering fish, $84 \pm 2 \%$ low-triggering fish and $6 \pm 1 \%$ high-triggering fish. When all tanks were considered together, each triggering category accounted for a different proportion of the group feed demand: $64 \pm 2 \%$ of total actuation activity was realized by the high-triggering fish (11 fish in total) and the remaining $36 \pm 2 \%$ of total actuation activity was attributed to the low-triggering fish, since zero-triggering
Table 1. Number of active days, mean number of daily feed demand acts and values converted into feed quantity expressed in $\%$ of the fish biomass present in the group for each high-triggering fish in each tank. Data on the number of daily feed demand acts and \% of the biomass are means \pm SE. Letters indicate statistical differences between high-triggering fish for the mean number of daily feed demand acts and values expressed in $\%$ of fish biomass $(p<0.05)$.

\begin{tabular}{cccccc}
\hline Tank & $\begin{array}{c}\text { Fish } \\
\#\end{array}$ & $\begin{array}{c}N \\
\text { active } \\
\text { days }\end{array}$ & $\begin{array}{c}\text { Mean number } \\
\text { of daily feed } \\
\text { demand acts }\end{array}$ & $\begin{array}{c}\text { \% of the fish } \\
\text { biomass }\end{array}$ & \\
\hline & & & $7.4 \pm 0.5 \&$ & $0.4 \pm 0.02 \&$ & \\
1 & 1 & $54 \& 32$ & $7.3 \pm 0.7$ & $0.4 \pm 0.04$ & $\mathrm{a}$ \\
& 7 & 66 & $17.4 \pm 1.4$ & $0.7 \pm 0.05$ & $\mathrm{~b}$ \\
& 34 & 44 & $16.5 \pm 1.4$ & $0.8 \pm 0.06$ & $\mathrm{~b}$ \\
\hline \multirow{2}{*}{2} & 3 & 186 & $16.5 \pm 0.7$ & $0.7 \pm 0.03$ & $\mathrm{~b}$ \\
& 17 & 18 & $6.3 \pm 1.0$ & $0.3 \pm 0.06$ & $\mathrm{a}$ \\
\hline & 18 & 155 & $23.0 \pm 1.5$ & $1.0 \pm 0.07$ & $\mathrm{~b}$ \\
3 & 21 & 12 & $6.5 \pm 1.9$ & $0.3 \pm 0.08$ & $\mathrm{a}$ \\
& 43 & 32 & $5.0 \pm 0.6$ & $0.2 \pm 0.03$ & $\mathrm{a}$ \\
\hline & 7 & 53 & $14.1 \pm 1.1$ & $0.6 \pm 0.05$ & $\mathrm{c}$ \\
4 & 13 & 35 & $3.8 \pm 0.4$ & $0.2 \pm 0.02$ & $\mathrm{a}$ \\
& 17 & 67 & $7.5 \pm 0.8$ & $0.3 \pm 0.04$ & $\mathrm{~b}$ \\
\hline
\end{tabular}

fish did not make any feed demand. During the experiment, there were 2 to 3 high-triggering fish per tank, generally only one individual was in this category at a time and partitioning among categories remained stable over time (Millot et al. 2008). We observed changes in the identity of the fish that took the high-triggering role in a tank. These changes could be related to a measuring day on four occasions, but in 5 other cases the changes appeared spontaneously (Fig. 1). Mean duration of individual high-triggering activity was $63 \pm 16$ days, but varied from 12 to 186 days (Table 1 ) and was not significantly different between tanks $\left(F_{3,7}=0.27, p>0.05\right)$. After a high-triggering period, an individual became low- or a zero-triggering. Such an individual could however become high-triggering once again some time later (Fig. 1, tank 1, fish \# 1). The transition period between two high-triggering fish in a tank was on average $4 \pm 4$ days.

The number of daily feed demand acts per group was different between tanks $\left(F_{3,769}=22.90, p<0.05\right)$. Means for the entire experimental period came to $22 \pm 1$ acts per day in tanks 1 and 2, $27 \pm 1$ in tank 3 and $15 \pm 1$ in tank 4 (Fig. 3). In terms of fish biomass this represented $0.9 \pm 0.03$ for tank $1,1.1 \pm 0.04$ for tanks 2 and 3 and $0.7 \pm 0.04 \%$ for tank $4\left(F_{3,769}=19.59\right.$, $p<0.05)$.

The number of daily feed demands realized by lowtriggering fish slightly decreased over time for tanks 1, 2 and 3 but slightly increased for tank 4 (Fig. 2).

Generally, during its active triggering period, a hightriggering fish made on average $4 \pm 1$ to $23 \pm 2$ daily feed demand acts, which represented $0.2 \pm 0.02$ to $1.0 \pm 0.07 \%$ of the fish biomass present in the tank (Table 1). The mean number of daily feed demands could be significantly different among successive high-triggering fish in the same tank (Table 1). There was also a significant difference between tanks for the mean daily number of feed demands by high-triggering fish $\left(F_{3,787}=44.51, p<0.001\right)$ and for the data converted into percentage of fish biomass present in the tank $\left(F_{3,787}=39.60\right.$, 

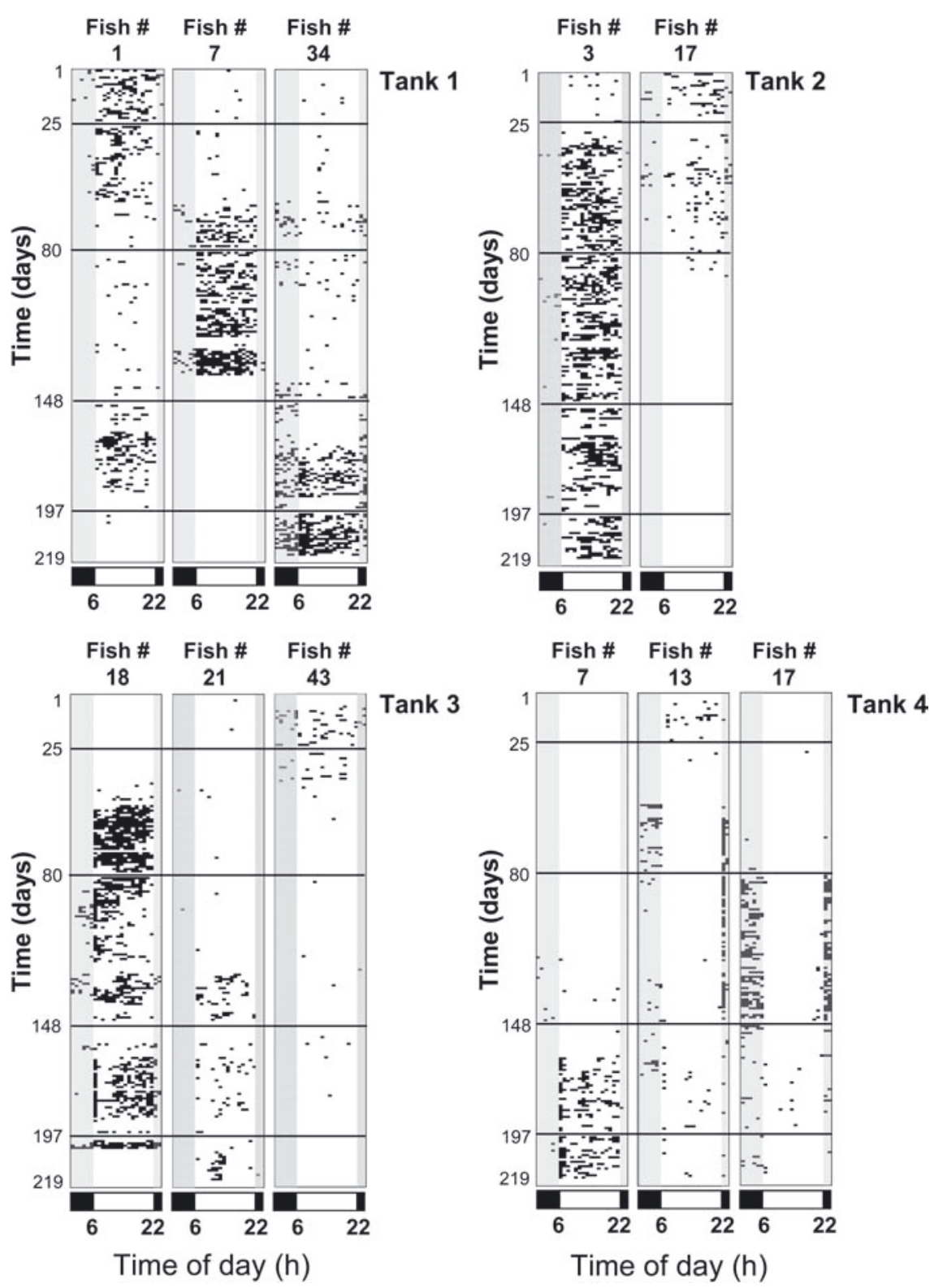

Fig. 1. Actogram showing feed demand activity of high-triggering fish in each tank. Feed demand acts were summed per clock hour and represented by black squares. The $X$-axis represents time of the day (hours), and $Y$-axis represents experimental days. The white and black bars on the bottom indicate the spans of light and darkness, respectively. The horizontal black lines represent the measuring days.

$p<0.001)$. Indeed, when all high-triggering fish in tank 4 were considered together, they realized $7 \pm 1$ daily feed demand acts, which was significantly less than the mean daily feed demand acts by high-triggering fish in tank $1(13 \pm 1)$, tank $2(15 \pm 1)$ or tank $3(19 \pm 1)$. The same differences were observed with data converted into percentage of fish biomass present in the tanks $(0.3 \pm 0.02 \%$ for tank $4 ; 0.6 \pm 0.03 \%$ for tank $1 ; 0.7 \pm 0.03 \%$ for tank 2 and $0.8 \pm 0.06 \%$ for tank 3 ).

When two high-triggering fish occurred in the same tank during the same period of time, the daily feed demand act number could increase by $18 \pm 3 \%$. During these periods, or after a measuring day, the number of feed demand acts realized by high-triggering fish could be very large, and was sometimes above 60 acts per day. These periods were often accompanied by pellet wastage (up to $70 \%$ of the quantity distributed, Millot et al. 2008). In general, such a period was ended with a change in the highest-triggering individual, with which the food wastage ended.

\subsection{Group and individual feed demand rhythm}

Group feed demand was characterized by 2 or 3 activity peaks per day (Fig. 3, black line). When fish in the tank were nocturnal, the activity peak was at 22:00, and when fish were diurnal, the activity peak was at 06:00 and/or at 12:00 (Fig. 3). For each feed demand activity peak, high-triggering fish realized an average $67 \pm 3 \%(\min =59 \%, \max =80 \%)$ of the total feed demand acts number in the tank (Fig. 3). 

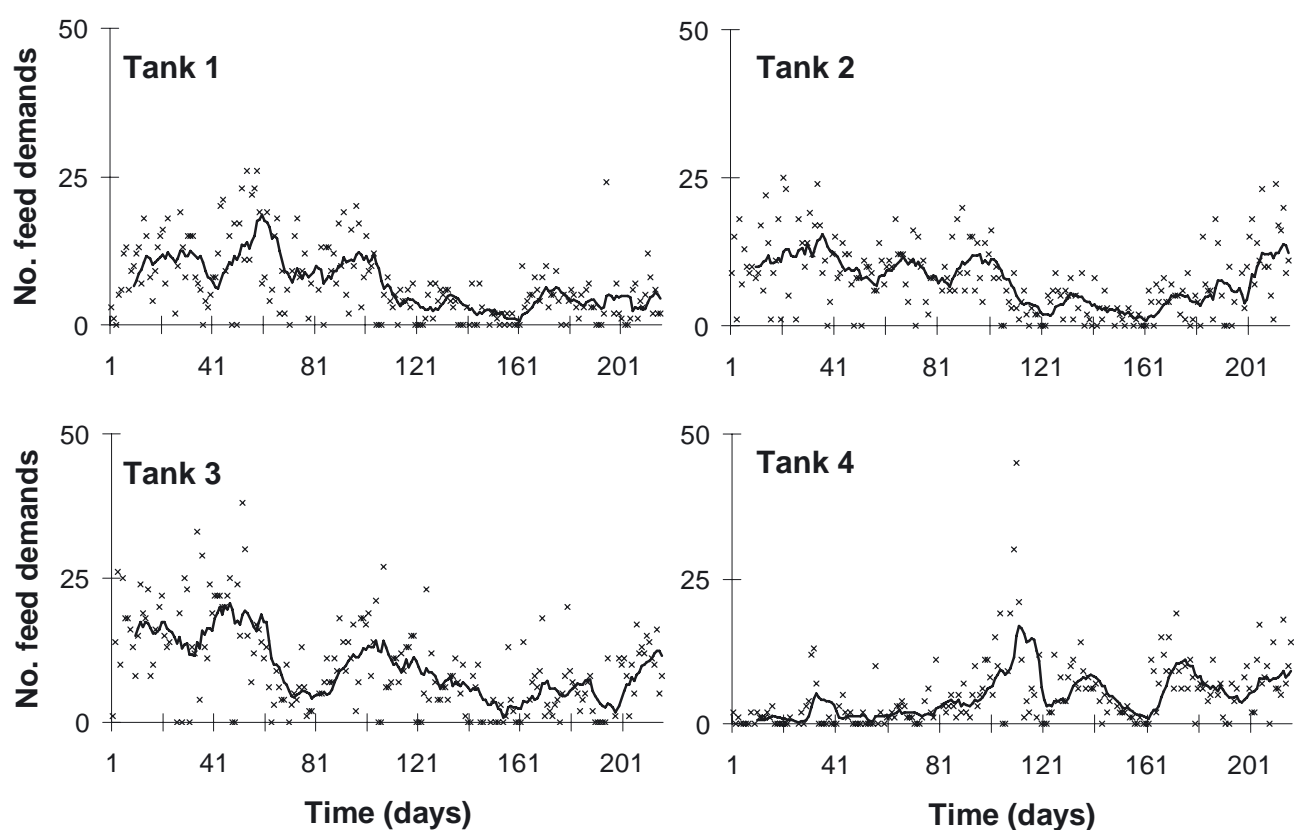

Fig. 2. Feed demand activity of all low-triggering fish in each tank over time; the $X$-axis represents experimental days and $Y$-axis represents the sum of feed demands realized by all low-triggering fish in the tank. The black line represents the moving mean based on 10 days.
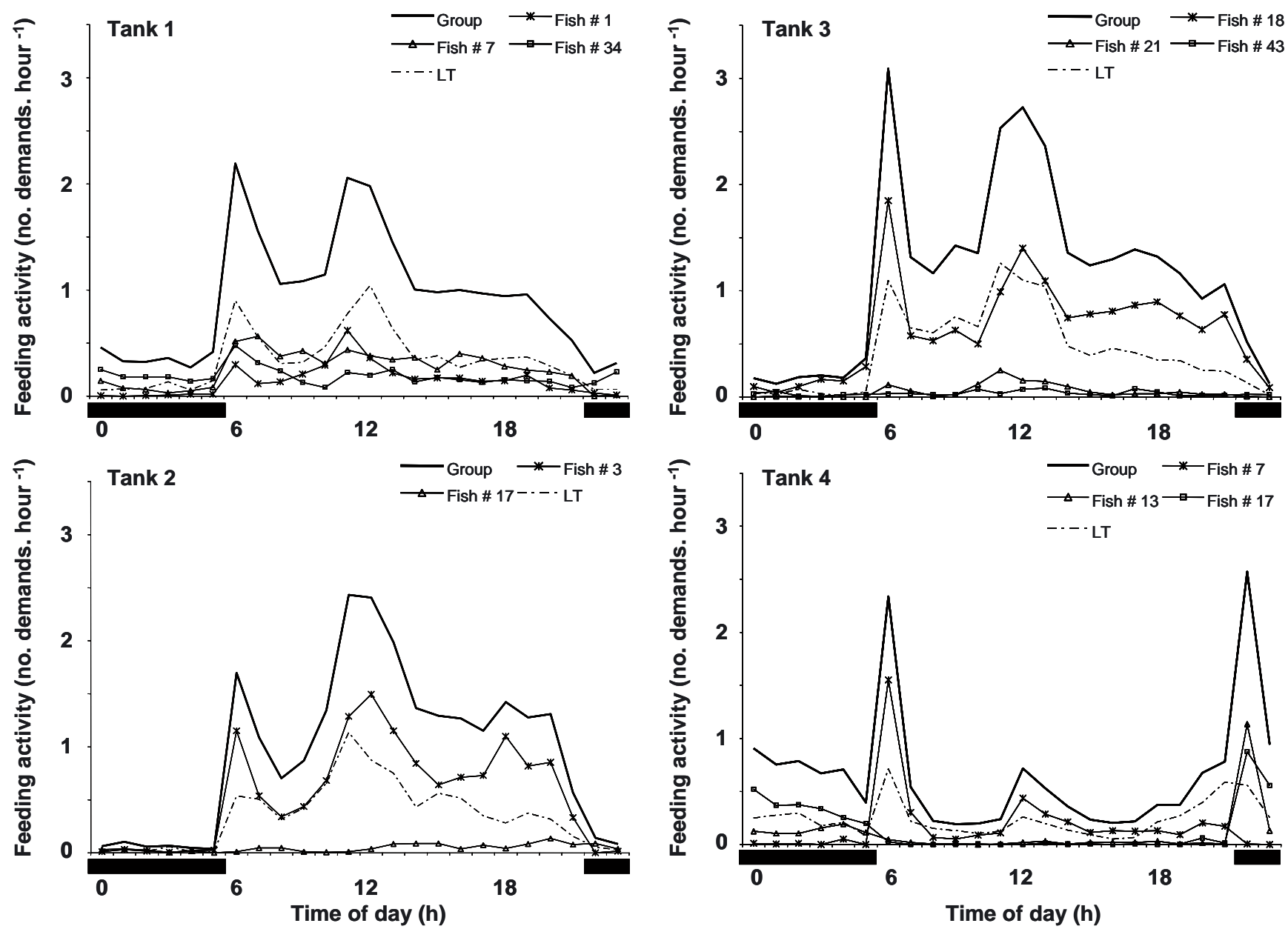

Fig. 3. Mean hourly feed demand (sum of feed demand acts per every clock hour averaged over the entire experimental period) for total group, low-triggering (LT) and high-triggering fish and for each tank. The $X$-axis represents time of the day (hours), and $Y$-axis represents mean clock hour feed demand acts number over 219 days. The black bars on the bottom indicate the spans of darkness. 
The feed demand of low-triggering fish (Fig. 3, dotted line) followed the rhythm of the highest-triggering fish, with the same activity peaks. When the high-triggering fish was nocturnal, the rhythm of the other fish in the tank was also nocturnal (Fig. 3, tank 4), and when it was diurnal, all the fish in the tank were diurnal (Fig. 3, tanks 1, 2 and 3). The more this hightriggering fish had a long and intensive feed demand activity period, the more it had a directing influence on the rhythm of the other fish (Table 1, Fig. 3, fish \# 3 tank 2, and fish \# 18 tank 3).

Most of the high-triggering fish were characterized by a well defined circadian rhythm: 9 high-triggering fish were diurnal and 2 were nocturnal (Fig. 1).

When there were two high-triggering fish in the same tank during the same period of time, they presented different feed demand activity rhythms. Therefore, when one high-triggering fish made most of its feed demand during a specific period, the second high-triggering fish made its majority of feed demand in another period (e.g. fish \# 13 and fish \# 17 in tank 4, Fig. 1). The first high-triggering fish in tank 4 (fish \# 13) made most of its feed demand between 00:00 and 06:00 but when a second individual (fish \# 17) also became a high-triggering fish in the same tank, and made the majority of its feed demand during this same period (00:00 to 06:00), then fish \# 13 changed its feed demand period and concentrated it at 22:00 instead. The same phenomenon was seen between fish \# 1 and fish \# 34 in tank 1 at the end of the experimentation period (Fig. 1).

Fish manipulation for the measurement days did not seem to have any effects on feed demand rhythms of high-triggering which remained either nocturnal or diurnal.

\section{Discussion}

\subsection{Feed demand activity}

The sea bass used in this experiment were naive with respect to the self-feeding apparatus, and significant triggering activity only began around 10 days after the experiment started. These results presented in Millot et al. (2008), were equivalent to observations by Kentouri et al. (1992), Covès et al. (2006) and Di Poi et al. (2008). Tank 4 showed a delay and lower self-feeder activation than other tanks however, highlighting that the time needed for learning could differ not only between species, but also between groups of the same species (Kentouri et al. 1992). This difference in learning ability could be explained by the particular group composition in each tank and the fact that tank 4 contained less fish than the other three tanks. Brown et al. (1992) reported that a lower density could lead to increased social interactions within a group in Arctic charr, Salvelinus alpinus (L.), and Kentouri et al. (1992) showed that "dominance" behaviour of sea bass, up to territoriality, could induce learning delays. In our experiment, however, there was no difference in density between tanks and no visible external signs of aggressive interactions between fish (no bites, damaged fins or missing scales were noticed). Additionally, Anthouard et al. (1986) showed that the difference in behaviour towards the feeder trigger could be explained by large variation in individual behaviour within a species, suggesting that the efficiency with which fish used the trigger as a tool depended on the particular skills of each individual. Furthermore, the fact that low-triggering fish in all tanks, excepted in tank 4 realized less and less feed demand over time seemed to show an establishment of individual specialization among the fish within the group. The atypical fish behaviour observed in tank 4, suggested that the number of fish present in the tank had a higher effect on fish learning ability and feeding behaviour than density had.

The duration of high-triggering activity in individual fish was variable but on average lasted about two months. The highest-triggering fish would then be replaced by another fish after a transition period of about 4 days. When the transition period between two high-triggering fish was longer, self-feeder activation and food wastage significantly increased (Millot et al. 2008). Chen et al. (2002) suggested that rainbow trout, Oncorhynchus mykiss (Walbaum) social status was determined by their capacity to use the self-feeder, and this capacity could also determine the individual social status within the group in sea bass (Di-Poï et al. 2007). However, changes of the hightriggering fish of a group in our experiment could appear either after fish manipulation (measuring days), which were a potential source of stress, or spontaneously. Millot et al. (2008) showed that high-triggering fish did not have higher initial length or mass than other fish, nor did they differ in physiological status (i.e. muscle composition, plasma and tissues biochemistry) but they did have a different specific growth rate during their activity period. Indeed, fish which became hightriggering were also characterised by a lower initial growth rate and would thus be expected to have a higher feeding motivation (Millot et al. 2008). Moreover, when a high-triggering fish lost this status, its growth rate generally return to a level equivalent to that of other fish. Thus, one hypothesis will be that this fish kept its high-triggering status as long as was necessary to recover a sufficient growth rate, and that consequently its feeding motivation decreased. This idea seems to be supported by the observations of Krause et al. (1992), who showed that positions of individuals in roach schools are dependent on their nutritional needs, with hungry fish occupying front positions only as long as is necessary for them to regain their nutritional balance. Together, our results and those of Krause et al. (1992) suggest that group members effectively take turns at being the feed demand leader.

\subsection{Group feeding directed by individual biological rhythm}

Besides highlighting the important influence of hightriggering fish on the quantitative aspects of group feeding (i.e. total amount of food consumed), this study also revealed that these fish had a high directing effect on the qualitative aspects of group feeding (i.e. rhythm). Indeed, the highesttriggering fish seemed to be the initiator of feed demand acts by the low-triggering fish, thereby directing the group feeding activity pattern. Sea bass feeding behaviour is characterized by the capacity to alternate daytime and night-time feeding patterns (Bégout Anras 1995; Sánchez-Vázquez et al. 1995a,b) according to seasonal variations in photoperiod, light intensity and temperature variation. In this experiment, the four tanks offered identical and constant conditions (light-dark phase, 
temperature and water quality) over a long period. Nevertheless, three tanks out of four displayed a diurnal feeding with a peak at dawn, as already observed by Anthouard et al. (1993) and Covès et al. (2006), while the other tank was nocturnal and its occupants started their daily feed demand at dusk. This nocturnal feed demand activity could not be unintentional self-feeder activation, since no uneaten pellets were recorded. A previous study described sea bass in different groups, held under similar conditions, displaying nocturnal and diurnal feeding patterns simultaneously (Sánchez-Vázquez et al. 1995b). In the present study, fish of the four groups showed spontaneous and complete inversion of their feeding pattern within a few days. These rhythm changes were initiated by the group feed demand leader, which presented a well defined circadian rhythm based on 24 hours. Indeed, the group feed demand rhythm followed the high-triggering fish demand feeding rhythm exactly. When the highest-triggering fish was nocturnal, the totality of feed demands by low triggering fish was realized at night. In contrast, when the highest-triggering fish was diurnal, the majority of feed demands by low triggering fish were realized during the light and twilight periods. The fact that the low-triggering fish feed demands peaks occurred simultaneously with those of high-triggering fish could be explained either by copy behaviour or more probably by the stimulating action on fish appetite of the first pellets reaching the water and thus inducing further triggering activity.

These differences in demand feeding rhythm between high-triggering fish could be explained by the fact that sea bass shows a high degree of dependence on light conditions (Sánchez-Vázquez et al. 1994), although feeding rhythm could also be conditioned by individual's own clock (Madrid et al. 2001). Variability is one of the characteristics of circadian rhythms in fish. The appearance of circadian rhythms varies within a species and even within a single individual (Madrid et al. 2001). High inter-individual variability in feeding patterns was observed in sea bass and goldfish (Carassius auratus L.) housed individually and under group-housing conditions (Sánchez-Vázquez et al. 1995a,b, 1996). Three mechanisms have been proposed to account for individual differences in fish behaviour: environmental variables, phenotypic differences and behaviour of other individuals (Krebs and Davies 1981; Partridge and Green 1985). In the present study, the most relevant mechanism to explain this difference seems to be the individual biological rhythm of the feed demand leader within the group. However, the prominent role of this high-triggering fish in directing group feeding could be decreased by the appearance of a second feed demand leader in the tank. Indeed, when two high-triggering fish were present in the same tank during the same period of time, they seldom activated the selffeeder with the same hourly rhythm, as also shown by Covès et al. (2006). In our study, such shared periods were short and were always followed by a change of high-triggering fish within the group. Thus, this temporal partitioning might be explained by a transitory imbalance in the group social structure or by social interactions between these two high-triggering fish.

There is increasing evidence that the properties of fish feeding rhythms have similarities with those of other vertebrates (Boujard and Leartherland 1992; Madrid et al. 2001).
According to their feeding preferences, populations of sea bass were originally classified as being diurnal, nocturnal or crepuscular and with the faculty to modify their feeding rhythm in a fast and complete way (Anthouard et al. 1993; Sánchez-Vázquez et al. 1995b). The present study has further highlighted that sea bass group demand feeding behaviour is not the sum of the feed demand behaviour of individuals, but is directed by the rhythm and behaviour of a single hightriggering fish. The regular changes in the individual fulfilling the role of highest-triggering fish in the tanks proved that it is not the identity of this fish that is the most important for the group, but its role as a feed demand leader.

Acknowledgements. We wish to thank N. Lachaussée, D. Leguay, P. Pineau and M. Prineau for their technical help. We also thank H. McCombie-Boudry for editing the English of this manuscript. This work was performed as part of the Integrated Research Project SEAFOODplus, contract no. FOOD-CT-2004-506359. We gratefully acknowledge the funding of this work by the European Union. This study was conducted under the approval of the Animal Care Committee of France under the official license of M.L. Bégout (17-010).

\section{References}

Anthouard M., Desportes C., Kentouri M., Divanach P., Paris, J., 1986, Étude des modèles comportementaux manifestés au levier par Dicentrarchus labrax, Diplodus sargus, Puntazzo puntazzo, Sparus aurata, et Lithognathus mormyrus (Poissons téléostéens), placés dans une situation de nourrissage auto-contrôlé. Biol. Behav. 11, 97-110.

Anthouard M., Kentouri M., Divanach P., 1993, An analysis of feeding activities of sea bass (Dicentrarchus labrax, Moronidae), raised under different lighting conditions. Ichthyol. Acta 16, 5973.

Aranda A., Madrid J.A., Zamora S., Sánchez-Vázquez F.J., 1999, Synchronizing effect of photoperiod on the dual phasing of demand-feeding rhythms in sea bass. Biol. Rhythm Res. 30, 392406.

Bardach J.E., Todd, J.H., 1970, Chemical communication in fish. In: Johnston J.W., Moulton D.G., Turk A. (eds.) Advances in chemoreception (New York) 1, pp. 205-240.

Bégout Anras M.L., 1995, Demand-feeding behaviour of sea bass kept in ponds: diel and seasonal patterns, and influences of environmental factors. Aquac. Int. 3, 186-195.

Boujard T., Leartherland J.F., 1992, Circadian rhythms and feeding time in fishes. Environ. Biol. Fish 35, 109-131.

Boujard T., Jourdan M., Kentouri M., Divanach P., 1996, Diel feeding activity and the effect of time-restricted self-feeding on growth and feed conversion in European sea bass. Aquaculture 139, 117127.

Boulos Z., Terman M., 1980, Food availability and daily biological rhythms. Neurosci. Biobehav. Rev. 4, 119-131.

Brown G.E., Brown J.A., Srivastava R.K., 1992, The effect of stocking density on the behaviour of arctic char (Salvelinus alpinus L.). J. Fish Biol. 41, 955-963.

Chen W.M., Mayumi N., Mitsuo T., 2002, Circadian rhythms and individual variability of self-feeding activity in groups of rainbow trout Oncorhynchus mykiss (Walbaum). Aquac. Res. 33, 491500 . 
Covès D., Beauchaud M., Attia J., Dutto G., Bouchut C., Bégout Anras M.L., 2006, Long-term monitoring of individual fish triggering activity on a self-feeding system: An example using European sea bass (Dicentrarchus labrax). Aquaculture 253, 385-392.

Dagnélie P., 1975, Théorie et méthodes statistiques. In: Applications agronomiques, Presses Agronomiques de Gembloux, Gembloux, Vol. 2.

Di-Poï C., Attia J., Bouchut C., Dutto G., Covès D., Beauchaud M., 2007, Behavioural and neurophysiological responses of European sea bass groups reared under food constraint. Physiol. Behav. 90, 559-566.

Di-Poi C., Beauchaud M., Bouchut C., Dutto G., Coves D., Attia J., 2008, Effects of high food-demand fish removal in groups of juvenile sea bass (Dicentrarchus labrax). Can. J. Zool. 86, 10151023.

Falcon J., Thibault C., Begay V., 1992, Regulation of the rhythmic melatonin secretion by fish pineal photoreceptor cells. In: Ali M.A. (eds.) Rhythms in fishes, New York, Plenum Press, pp. 167198.

Kentouri M., Divanach P., Batique O., Anthouard M., 1986, Rôle des individus conditionnés dans l'initiation à l'auto-nourrissage et dans l'adaptation à la captivité du loup Dicentrarchus labrax, 0+ sauvage, en période hivernale. Aquaculture 52, 117-124.

Kentouri M., Anthouard M., Divanach P., Paspatis M., 1992, Les modalités d'adaptation comportementale de populations de bars (Serranidae: Dicentrarchus labrax), soumises à un nourrissage auto-contrôlé. Ichthyol. Acta 15, 19-42.

Krause J., Bumann D., Todt D., 1992, Relationship between the position preference and nutritional state of individuals in schools of juvenile roach (Rutilus rutilus). Behav. Ecol. Sociobiol. 30, 177180.

Krebs J.R., Davies NB., 1981, An introduction to behavioural ecology, Blackwell, Oxford.
Madrid J.A., 1994, Question de swing. L'alimentation à la demande et les rythmes endogènes. Aqua Revue 52, 33.

Madrid J.A., Boujard T., Sánchez-Vázquez F.J., 2001, Feeding rhythms. In: Houliham D., Boujard T., Jobling M. (eds.) Food Intake in Fish, London, Blackwell Science, pp. 189-215.

Millot S., Bégout M.L., Person-Le Ruyet J., Breuil G., Di-Poï C., Pineau P., Roué M., Sévère A., 2008, Feed demand behaviour in sea bass juveniles: effects on individual specific growth rate variation and health (inter-individual and inter-group variation). Aquaculture 274, 87-95.

Partridge L., Green P., 1985, Intraspecific feeding specializations and population dynamics'. In: Ras Sibley R. (eds.) Behavioural ecology symposium, Oxford, British ecology society, Blackwell, pp. 207-226.

Sánchez-Vázquez F.J., Martinez M., Zamora S., Madrid J.A., 1994, Design and performance of an accurate demand feeder for the study of feeding behaviour in sea bass, Dicentrarchus labrax L. Physiol. Behav. 56, 789-794.

Sánchez-Vázquez F.J., Zamora S., Madrid J.A., 1995a, Light-dark and food restriction cycles in sea bass; Effect of conflicting zeitgebers on demand-feeding rhythms. Physiol. Behav. 58, 705714.

Sánchez-Vázquez F.J., Madrid J.A., Zamora S., 1995b, Circadian rhythms of feeding activity in sea bass, Dicentrarchus labrax L.: Dual phasing capacity of diel demand-feeding pattern. J. Biol. Rhythm 10, 256-266.

Sánchez-Vázquez F.J., Madrid J.A., Zamora S., Iigo M., Tabata M., 1996, Demand feeding and locomotor circadian rhythms in the goldfish, Carassius auratus: dual and independent phasing. Physiol. Behav. 60, 665-674.

Sánchez-Vázquez J.A., Azzaydi M., Martinez F.J., 1998, Annual rhythms of demand-feeding activity in sea bass: evidence of a seasonal phase inversion of the diel feeding pattern. Chronobiol. Int. 15, 607-622. 